Original Research

\title{
Predictors of Mortality among Patients Lost to Follow up Antiretroviral Therapy
}

\section{Putu Dian Prima Kusuma Dewi and Gede Budi Widiarta}

\author{
STIKES Buleleng, Bali, Indonesia
}

\begin{abstract}
Introduction: The death of HIV/AIDS patients after receiving therapy in Bali is the seventh highest percentage of deaths in Indonesia. LTFU increases the risk of death in PLHA, given the saturation of people with HIV taking medication. The level of consistency in the treatment is very important to maintain the resilience and quality of life of people living with HIV. This study aims to determine the incidence rate, median time and predictors of death occurring in LTFU patients as seen from their sociodemographic and clinical characteristics.
\end{abstract}

Methods: This study used an analytical longitudinal approach with retrospective secondary data analysis in a cohort of HIV-positive patients receiving ARV therapy at the Buleleng District Hospital in the period 2006-2015. The study used the survival analysis available within the STATA SE 12 software

Results: The result showed that the incidence rate of death in LTFU patients was 65.9 per 100 persons, with the median time occurrence of 0.2 years ( 2.53 months). The NNRTI-class antiretroviral evapirens agents were shown to increase the risk of incidence of death in LTFU patients 3.92 times greater than the nevirapine group (HR 3.92; $\mathrm{p}=0.007$ (CI 1.46-10.51). Each $1 \mathrm{~kg}$ increase in body weight decreased the risk of death in LTFU patients by 6\% (HR 0.94; p = 0.035 (CI 0.89-0.99).

Conclusion: An evaluation and the monitoring of patient tracking with LTFU should be undertaken to improve sustainability. Furthermore, an observation of the LTFU patient's final condition with primary data and qualitative research needs to be done so then it can explore more deeply the reasons behind LTFU.

\section{ARTICLE HISTORY}

Received: Nov 14, 2017

Accepted: August 02, 2018

\section{KEYWORDS}

hiv/aids; buleleng district hospital; survival analysis

\section{CONTACT}

Putu Dian Prima Kusuma Dewi

$\triangle$ dian_pkd@yahoo.co.id $\doteqdot$ STIKES Buleleng, Bali, Indonesia

Cite this as: Kusuma Dewi, P., \& Widiarta, G. (2018). Predictors of Mortality among Patients Lost to Follow up Antiretroviral Therapy. Jurnal Ners, 13(1),114-121. doi:http://dx.doi.org/10.20473/in.v13i1.6568

\section{INTRODUCTION}

The epidemic and mortality rate of human immunodeficiency virus (HIV) and Acquired Immune Deficiency Syndrome (AIDS) infections are still a global health problem. Globally, with the presence of antiretroviral (ARV) therapy, new infections and deaths are reported to have declined up to 2011 by $86 \%$ and $18 \%$, respectively. Contrary to the ARV coverage, only $50 \%$ were treated and mostly adults were at a loss to follow up (LTFU). This condition indicates a gap in the access to antiretroviral therapy (UNAIDS, 2013a). The retention rate for people taking antiretroviral therapy (ART) has declined over time, from about $86 \%$ at 12 months to $72 \%$ at 60 months (UNAIDS, 2013a).

The death of HIV / AIDS patients after receiving therapy in Bali is the seventh highest percentage in Indonesia. This figure is still below the national death rate $(18.04 \%)$, but is still far from the target of zero AIDS-related deaths (ASEAN, 2011). The number of cumulative AIDS cases in Bali is 4,261, with Denpasar City having the highest number 2,113 (49,59\%), second the Regency of Buleleng 593 (13,92\%), and third, the Regency of Badung 550 (12,91\%) (Kemenkes RI, 2014). The data shows Buleleng District as the second highest district for HIV / AIDS cases in Bali with a higher cumulative number of LTFU patients compared with Denpasar and

Badung regencies, at 211 (26.08\%) out of 1394 PLHAs with ARV therapy up to November 2013. This occurs considering that the area of Buleleng is large with limited access to therapy. It is only available in Singaraja Town, namely RSUD Buleleng. Buleleng is a high spot for HIV/AIDS cases with considerable access, such as to the Gerokgak and Sawan sub- 

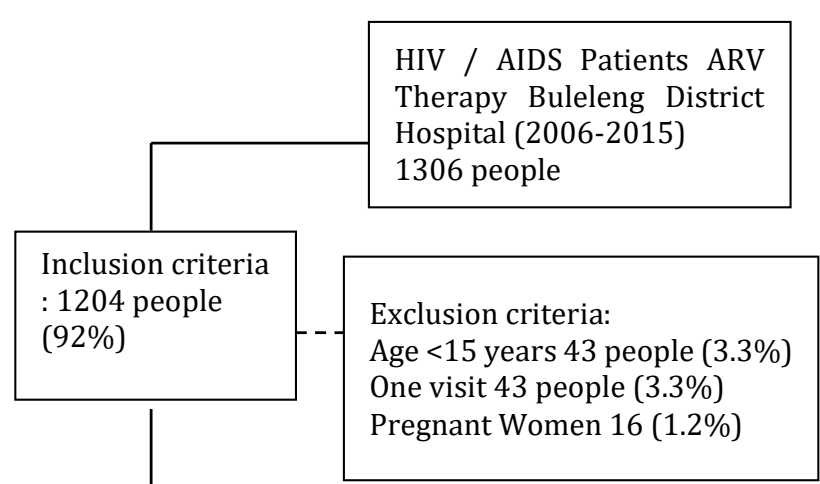

Patient in Buleleng District

Hospital 1204 (92\%)

- Still ARV therapy 842 (69.9\%)

- Died 112 (9.3\%)

- LTFU $180(14.9 \%)$

- LTFU-Died 37 (3.1\%)

- LTFU- Life $6(0.5 \%)$

- Stop Treatment $5(0.4 \%)$

- Refer out 22 (1.8\%)

Figure 1 Flow chart of Respondents

districts (www.bulelengkab.go.id). The limited access make conditions and the discipline level of PLHA sufferers become strategic points that need to be studied, with the intention of reducing the risk of death and LTFU of PLHA.

ARV therapy requires high adherence and monitoring to suppress viral replication, to improve immunology and clinical outcomes, to reduce the risk of ARV drug resistance, and to reduce the risk of HIV transmission (WHO, 2013). The level of consistency and adherence of PLHAs remains a problem in Indonesia, including Bali where there is a good HIV prevention program. However, little is known about the predictors of death in LTFU patients.

Data related to the death rate of LTFU patients has not been reported on yet, although the data is important in order to know the last condition of LTFU patients while they are undergoing therapy. Death is the most common reason recorded for 233 (47.94\%) of those experiencing LTFU (Wubshet et al, 2013). LTFU increases the risk of death in PLHAs (AlvarezUria et al, 2013). LTFU incidence continues to increase every year, given the saturation of PLHAs consuming drugs. The level of consistency in treatment is very important to maintain the resilience and quality of life of PLHAs. The incidence of LTFUs in patients receiving antiretroviral therapy varies, according to several studies other countries indicating that the longer the antiretroviral therapy is received, then the incidence and percentage of LTFU is also greater (Kate et al. 2014; Mugisha et al., 2014). Studies in African, European, American and Asian countries reporting on the predictors of death in HIV/AIDS patients still show inconsistent results in relation to some of the variables. These variables include age (Alvarez-Uria et al., 2013), gender (Odafe et al., 2012) and medication companion (Lamb et al., 2012).
Longitudinal research is important to determine the success of the ARV therapy programs that have been taking place. The LTFU indicator of the health facility setting of government hospitals is generally less than optimal for outreach programs, compared to private clinics. Most of the population are local residents. This research is expected to identify the predictors of deaths in LTFU patients undergoing ARV therapy in the general population in Bali, especially Buleleng District, which has not been done previously. This study will later contribute to practitioners and program holders on monitoring and evaluating the success of ARV treatment of PLHIV patients, especially in government hospitals.

\section{MATERIALS AND METHODS}

This study aims to determine the incidence rate, median time and predictors of death occurring in LTFU patients as seen from the sociodemographic and clinical characteristics. The method of study was an analytical longitudinal study with retrospective secondary data analysis in a cohort of patients receiving ARV therapy at the District General Hospital of Buleleng District from 2006 to 2015. This study used secondary data from the medical records of PLHA patients receiving ART and ARV registers contained in the VCT Polyclinic of Buleleng Hospital. Surveys via telephone and home visits were made for special patients with LTFU accompanied by field officers from NGOs. The survey aimed to check on the status of the LTFU patients recorded in the medical record, so that then we could more accurately know the person's last condition (outcome) such as death, still live or loss. The extracted medical records, used as the study sample, were the patients receiving ART in the period January 2006 to December 2015.

The first step taken before the data extraction was to complete the permit application sent to the Buleleng District Hospital. The first step involved was to draw up a permit for research in Buleleng District Hospital, including the recommendation of research to the National Unity and Politics Board Buleleng District and the Ethical Clearance process of the Ethics Commission Faculty of Medicine Udayana University/Sanglah Hospital Denpasar. The numberletter of the permit for research in Buleleng District Hospital is No: 070/1958/SDM/VI/RSUD/2017, the number of recommendation from the National Unity and Politics Board Buleleng District is No.070/279/BKBP/2017 and the number of the ethical clearance was No.2611/UN.14.2/KEP/2017.

The data as shown in the figure 1 was collected by extraction from the medical records and the ARV registers of each PLHA antiretroviral period from 2006 to December 2015 at the VCT service Edelweies Buleleng District Hospital, to form the inclusion criteria. Next, the data was written in hard copy form and then made into a soft copy (in the form of Microsoft excel).

This research study was conducted in the VCT Eldeweies clinic of Buleleng District Hospital from 
April 2017 to November 2017. The dependent variable was death in LTFU patients who had undergone ARV therapy with the event date as the date or month of the last visit of the LTFU patient declared dead through the data on their medical records, ARV registers and survey results (tracking) via telephone and home visits. The independent variable consisted of their sociodemographic and clinical characteristics. The characteristics of sociodemography consist of age, sex, work status and if they were a drug conservator (PMO). The clinical characteristics included their CD4 cell count, WHO stage, type of NRTI ARV, and NNRTI ARV type. The total population in the study up to July 31, 2014 was 1,013 patients. This population was limited via the inclusion criteria to HIV/AIDS patients receiving ARV therapy under LTFU. The exclusion criteria established in this study were pregnant women, $<15$ years of age and non-random identities.

The study will be limited to a specific timeframe from 2006 to 2014, and the recruitment of the study subjects was performed early with those receiving antiretroviral therapy as the baseline (initial observation). Based on the large sample calculations, some of the most commonly found variables had links with those who had died in LTFU. It showed a minimum sample of 70 people with assumptions on the dead group (70 exposed groups) and the nondead (control group) group of 70 people. However, the sample to be used in this study consisted of all of the samples that met the inclusion criteria; as many as 1,204 patients with 223 patients included in LTFU so then the minimum sample size was met. All of the samples used were with consideration to the use of the secondary data to avoid incomplete data being available. Consideration needed to be given as to the use of a larger sample. The samples used in the study met the inclusion criteria bearing in midn the consideration of avoiding incomplete or missing secondary data.

The secondary data was in the form of a cohort of LTFU patients receiving ARVs in the 2006 to 2015 period recorded in the medical records. The primary data was obtained through survey results (home visits and via telephone), assisted by field officers to determine the condition of the patients with LTFU. All of the samples that met the inclusion criteria were included as the study sample. This selection was done not to reduce the strength of research due to missing data that can be found in the patient's medical record but so then the missing data was not focused on the same variable in each patient. Patients who had started ARV therapy and met the inclusion criteria were included as the study sample.

The analysis conducted in this study used survival analysis, using STATA SE 12 software. Univariate analysis was used to obtain the incidence rate of death rate per 100 person according to a years and hazard ratio, in addition to the median time of LTFU occurrence from the beginning of the year of the patient using ARV until the end of the observation year. The bivariate analysis resulted in a p value and survival rate that was used to see the significance of the differences between the respective groups. The value of the crude Hazard Ratio (HR), p specific, and $p$ of HR crude from each independent variable to LTFU were performed using Cox Proportional Hazard Modified with a 95\% confidence level. The parm test was used when the nominal independent variable was for three or more categories and we used a test for the trends when the ordinal data or intervals were in two or more categories.

Multivariate analysis with Cox Regression with the chosen selection method used was the backward method where one by one, the insignificant variables were removed from the model until the final model was obtained. The proportional hazard test was performed on the last multivariate model which aimed to check the proportional model produced when the model was said to be proportional, with a $\mathrm{p}$ $>0,05$.

\section{RESULTS}

The results achieved from this study in accordance with the research objectives were as many as 1,306 patients treated in the period 2006 to December 2015. The data recorded until December 2015 descriptively analysed as many as 223 people (18.5\%) patients with LTFU. The results of the study through the ARV registery data and the survey conducted together with the field officer found that LTFU patients who died was as many as 37 people (3.1\%), LTFU without further information was 180 people $(14,9 \%)$, and detected LTFU patients who were still alive but did not continue their treatment was as 6 people $(0.5 \%)$. The data obtained was then input into the Excel form in accordance with the predetermined variables for subsequent analysis using the STATA SE 12 software.

The number of patients on antiretroviral therapy in Buleleng District Hospital from 2006 up to

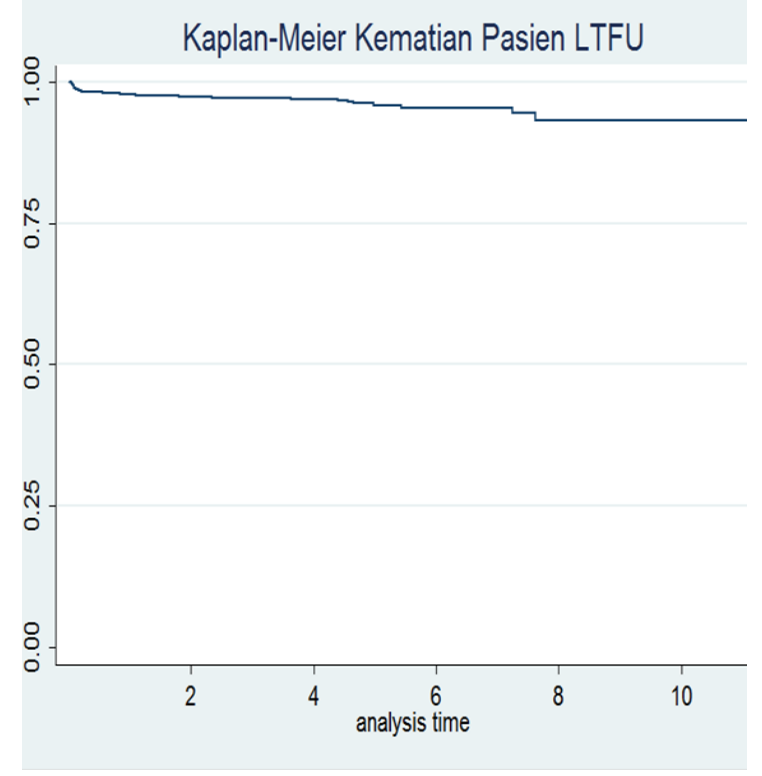

Figure 2 Kaplan Meier Graphic of LTFU Patient Death 
Table 1. Sociodemographic and Clinical Characteristics of Died in LTFU Patients and No Died in LTFU Patients

\begin{tabular}{|c|c|c|c|}
\hline Sociodemographic & $\begin{array}{c}\text { Died in LTFU Patients } \\
(\mathrm{N}=37) \\
n(\%)\end{array}$ & $\begin{array}{c}\text { Not Died } \\
\text { in LTFU Patients } \\
(\mathrm{N}=1167) \\
n(\%)\end{array}$ & $\begin{array}{l}\text { Total } \\
\text { n(\%) }\end{array}$ \\
\hline 1 & 3 & 2 & 4 \\
\hline Median of Age (IQR)* & $33(30-38)$ & $31(27-37)$ & $31(27-37)$ \\
\hline \multicolumn{4}{|l|}{ Sex } \\
\hline Female & $13(2.9)$ & $433(97.1)$ & $446(100)$ \\
\hline Male & $24(3.1)$ & $734(96.8)$ & $758(100)$ \\
\hline \multicolumn{4}{|l|}{ Adherence support } \\
\hline Yes & $30(2.9)$ & $1002(97.1)$ & $1032(100)$ \\
\hline No & $7(4.1)$ & $165(95.9)$ & $172(100)$ \\
\hline \multicolumn{4}{|l|}{ Fungtional Status } \\
\hline Bed & $8(2.3)$ & $334(97.7)$ & $342(100)$ \\
\hline Ambulatory & $19(3.8)$ & $475(96.1)$ & $494(100)$ \\
\hline Working & $9(3.5)$ & $245(96.5)$ & $254(100)$ \\
\hline \multicolumn{4}{|l|}{ NRTI } \\
\hline Tenofovir & $11(5.5)$ & $191(94.5)$ & $202(100)$ \\
\hline Stavudine & $5(5.4)$ & $87(94.6)$ & $92(100)$ \\
\hline Zidovudine & $21(2.3)$ & $881(97.7)$ & $902(100)$ \\
\hline \multicolumn{4}{|l|}{ NNRTI } \\
\hline Evapirens & $12(4.1)$ & 277 (95.9) & $289(100)$ \\
\hline Nevirapine & $25(2.8)$ & $881(97.2)$ & $906(100)$ \\
\hline \multicolumn{4}{|l|}{ WHO Stage } \\
\hline Stadium $1 \& 2$ & $8(3.7)$ & $206(96.3)$ & $214(100)$ \\
\hline Stadium $3 \& 4$ & $27(3.2)$ & $811(96.8)$ & $838(100)$ \\
\hline CD4 & $26(17-50)$ & $65(23-165)$ & $64.5(23-164.7)$ \\
\hline Weight & $47.5(38.5-55)$ & $50(45-57)$ & $50(44-55)$ \\
\hline
\end{tabular}

* test normality spahiro-wilk not normally distributed so used median (IQR)

December 2015 was 1,306 people. The number of samples meeting the inclusion criteria were 1,204 people (92\%) who received therapy and had a minimum of two visits, while those not meeting the inclusion criteria consisted of 43 people (3.3\%) with one visit, 16 people (1.2\%) who were pregnant an 43 people ( $3.3 \%)$ under the $<15$ years old. The characteristics of the study subjects were described based on their sociodemographic and clinical characteristics. The sociodemographic and clinical characteristics was the data collected at the beginning of the observation. The related descriptions of the sample's characteristics have been presented in tabular form, comparing the LTFU patient's death to each characteristic as in Table 1.

The number of PLHAs experiencing deaths in LTFU patients in Buleleng District Hospital was 37 people $(3.1 \%)$. The incidencerate of death in LTFU patients was 65.9 per 100 people with a median time (50\%) occurrence of 0.2 years (2.53 months). More than half of the respondents earned less than 2.4 million rupiah per month; $55.3 \%$ in the intervention group and $57.3 \%$ in control group. In terms of the relationship with the students, both groups were almost similar in that the respondents were taking care of their biological children, with the data showing $89.3 \%$ in the intervention group and $90.3 \%$ in the control group respectively

Kaplan Meier's analysis in Figure 2 above shows that for all of the PLHAs receiving antiretroviral therapy, 50\% were at risk of death among the LTFU patients in the first year of therapy or around 2.53 months. This can be seen from the curve drawing of the median time for observation

Bivariate analysis of the nine variables at the beginning of observation in the table 2 showed that only two of the variables, weight and the group of NRTIs (zidovudine), were statistically related. Each 1 $\mathrm{kg}$ increase in weight reduced the risk of death in the LTFU patients by $6 \%$ with $\mathrm{HR}=0.94 ; 95 \%$ CI 0.89 0.99; $\mathrm{p}=0.02$ ). Patients taking zidovudine-type ARVs reduced their risk of death in LTFU patients with HR $=0.32 ; 95 \%$ CI $0.15-0.69 ; p=0.01$ ). HIV-positive people who did not have a PMO were 1.57 times more at risk than those with a PMO (HR $=1.57 ; 95 \%$ CI 1.01 2.45; $p=0.045)$. Furthermore, HIV-positive people who did not have a PMO were of the male gender 1.1 times more than the average, their functional status being ambulatory was 1.37 times greater and had a 1.47 times greater chance of death, but statistically, it showed no meaning.

Multivariate analysis was needed to look at the most powerful and significant relationship to death among the LTFU patients concerning several variables related to the bivariate analysis. The variables included in the multivariate analysis were the variables having $p<0.25$ and the correlated variables found through the reference studie,s which were age, body weight, gender, medication control, Cd4 level, clinical stage, NRTI class and NNRTI group. 
Table 2. Predictor of Death in Loss to Follow Up Patient

\begin{tabular}{|c|c|c|c|c|c|c|c|}
\hline Variable & & crude HR & $95 \% \mathrm{CI}$ & $\mathbf{p}$ & aHR & 95\% CI & $\mathbf{p}$ \\
\hline 1 & 2 & 3 & 4 & 5 & & & \\
\hline \multicolumn{8}{|l|}{ (IQR)* } \\
\hline \multirow[t]{2}{*}{ Sex } & Female & 1.00 (reff) & & & & & \\
\hline & Male & 1.1 & $0.56-2.17$ & 0.76 & & & \\
\hline \multicolumn{8}{|l|}{ Adherence support } \\
\hline & Yes & 1.00 (reff) & & & & & \\
\hline & No & 1.37 & $0.60-3.14$ & 0.44 & & & \\
\hline \multicolumn{8}{|l|}{ Fungtional Status } \\
\hline & Bed & 1.00 (reff) & & & & & \\
\hline & Ambulator & 1.37 & $0.60-3.13$ & 0.45 & & & \\
\hline & Working & 1.47 & $0.56-3.81$ & 0.43 & & & \\
\hline \multicolumn{8}{|l|}{ NRTI } \\
\hline & Tenofovir & 1.00 (reff) & & & & & \\
\hline & Stavudine & 0.70 & $0.23-2.12$ & 0.53 & & & \\
\hline & Zidovudine & 0,32 & $0.15-0.69$ & $0.01^{*}$ & & & \\
\hline \multicolumn{8}{|l|}{ NNRTI } \\
\hline & Nevirapine & 1.00 (reff) & & & 1,00 (ref) & & \\
\hline & Evapirens & 1.37 & $0.86-3.49$ & 0.118 & 3.92 & $1.46-10.5$ & 0.01 \\
\hline \multicolumn{8}{|l|}{ WHO Stage } \\
\hline & Stadium $1 \& 2$ & 1.00 (reff) & & & & & \\
\hline & Stadium $3 \& 4$ & 0.83 & $0.37-1.84$ & 0.66 & & & \\
\hline CD4 & & 0.99 & $0.99-1.00$ & 0.43 & & & \\
\hline Weight & & 0.94 & 0.89-0.99 & $0.02 *$ & 0.94 & 0.89-0.99 & 0.035 \\
\hline
\end{tabular}

*p-value $<0.25$

Before doing the multivariate analysis, a collinearity test was conducted in order to know the effect of multi-collinearity. Collinearities can be discovered if there is a variable that has a correlation coefficient of more than 0.6 ( $r>0.6)$, which means that there is a strong correlation between the variables (Sugiyono, 2011). In this analysis, there were no variables having a correlation $>0.6$, so all covariate variables that met $\mathrm{p}<0.25$ could be included in the multivariate analysis.

Certain types of NNRTI-class antiretroviral evapirens have been shown to increase the incidences of death in LTFU patients 3.92 times greater than that of nevirapine (HR 3.92; $\mathrm{p}=0.007$ (CI 1.46-10.51). Each $1 \mathrm{~kg}$ increase in body weight can reduce the risk of death in LTFU patients by $6 \%$ (HR 0.94; $\mathrm{p}=0.035$ (CI 0.89-0.99)

\section{DISCUSSION}

The incidence rate of death in PLHAs experiencing LTFU within nine years at RSUD Buleleng was 65.4 per 100 people. This incidence rate is higher than that of 34.6 per 1,000 people over a period of five years (Bekolo et al., 2013). The risk of death in LTFU patients was 20 times higher than that of outpatientss (aHR 22.03; 95\% CI 20.05-24.21) (Cornell et al., 2014). The incidence rate in this study was lower compared to the TAHOD data covering 18 sites in the Asia Pacific region of 21.4 per $100 \mathrm{PY}$, but it was higher than the rate in Southeast Asian countries such as India (7.1 per $100 \mathrm{PY}$ ) and Vietnam ( 8.9 per 100 PY) (Zhou et al., 2012; Alvarez-Uria et al., 2013; Tran et al., 2013). Similarly, it can be compared with developed countries that tend to have lower incidence rates such as France (4.3 per $100 \mathrm{PY}$ ) and Europe (3.272 per 100 PY) (Lebouche et al., 2006; Mocroft et al., 2008). This difference is also due to the different cut-offs in defining LTFU i.e. one year from the last visit. A comparison with countries in Africa with the same cut off ( $\geq$ three months from the last visit) showed that the incidence rate for the findings in this study were lower, at 25.1 per $100 \mathrm{PY}$ (Western Kenya) (Ochieng-Ooko et al. 2010), 51.1 per 100 PY (Guinea Bissau) (Hønge et al., 2013) and 94.6 per 100 PY (Cameroon) (Bekolo et al., 2013).

The results of this study indicate that the LTFU patient death predictor that is statistically related to LTFU is NNRTI weight and the group of evapirens. Weight is a common reference used to assess nutritional status. LTFU PLHA deaths increased with a weight of 45 kilograms (Somi et al., 2012). People with HIV who start ARV therapy with a higher body weight will have a better health conditions. PLHAs with this condition tend to retain ARV therapy because they have benefited from the therapy. People with HIV who start therapy weighing less than $45 \mathrm{~kg}$ are more at risk of death and attrition. Losing weight> $10 \%$ is a common symptom experienced when infected with HIV (Dalal et al., 2008).

Other health conditions that can be used as a measure other than weight is BMI (body mass index). BMI (body mass index) $\leq 18.5 \mathrm{~kg} / \mathrm{m} 2$ indicates poor health condition that may decrease the patient's 
confidence in therapy so that LTFU is greater (aHR $1.51 ; 95 \%$ CI 1,23-1,87), supporting also the incidences of oral candidiasis with a low BMI (HR 1.36 95\% CI 1.02-1.82) (Hønge et al., 2013; Evans et al., 2013). In contrast, the increase in the BMI of each person decreased the incidence of LTFU (aHR, 0.97, 95\% CI 0.88-1.03) but did not otherwise show a significant relationship. Predictors among LTFU patients included BMI <17.5 (HR 2.4; 95\% CI 1.8-3.1) (Fox, Brennan, Maskew, MacPhail, \& Sanne, 2010). This is in line with the Ethiopian study which stated that PLHAs who weighed $\geq 60 \mathrm{~kg}$ had a $76 \%$ lower risk for LTFU than those with a weight $<40 \mathrm{~kg}$ (AHR 3.47 95\% CI 1.02-11.83). Those with a normal weight had confidence in their treatment and maintained it well (Haile \& Mekelle, 2014).

The ARV regimen consists of nucleoside reverse transcriptase inhibitors (NRTIs) and non-nucleoside reverse transcriptase (NNRTI). Groups that include the NRTI regimen are zidovudine (AZT), stavudine (d4T), lamivudine (3TC), didanosine (ddl), abacavir (ABC), tenofovir (TDF) and emtricitabine (FTC). The NNRTI regimens are nevirapine and efavirens. There is also a second line of protease inhibitor (PI) regimens such as lopinavir or ritonavir. ARV regimens related to drug characteristics, side effects and easy access to ARVs have an impact on the adherence of PLHAs (MoH RI, 2011a). Research conducted in Cameroon said that the use of the NNRTI nevirapine (NVP) regimen significantly reduced the risk of LTFU (aHR 0.75 CI0.57-0.99 p = 0.04), as well as on the use of the stavudine NRTI regimen (aHR $0.55 \mathrm{CI} 0.42-0.71$ ) and zidovudine (AZT) (aHR $0.59 \mathrm{CI}$ 0.45-9.77) (Bekolo et a, l., 2013). In contrast to studies in Ethiopia, the use of AZT increases LTFU risk by three times compared to the $\mathrm{d} 4 \mathrm{~T}$ regimens (Haile \& Mekelle, 2014).

HIV-positive people who received a substitution of their antiretroviral regimens during the treatment period were at a greater risk of LTFU (HR 5.2, 95\% CI 3.6-7.3). This is similar to studies in India who reported that substitution could be a risk factor for ART failure (Alvarez-Uria et al., 2013; Berheto et al., 2014). The majority of regimen substitution cases are caused by drug reactions, such as when patients may become concerned about the side effects and effectiveness of the new drugs.

\section{CONCLUSION}

The correct and complete recording of patient addresses and phone numbers, and reviewing the patient relationship with their PMO, was the most important part of recording for tracking purposes related o patient absence during scheduled visits. An evaluation and the monitoring of patient tracking with LTFU should be undertaken to improve sustainability. Furthermore, an observation of the LTFU patient's final condition with primary data and qualitative research needs to be done so then it can explore more deeply the reasons behind LTFU. This is to know how to anticipate LTFU. Observation time with the secondary data also needs to be added to better know the success of therapy.

\section{REFERENCES}

Alvarez-Uria, G., Naik, P. K., Pakam, R., \& Midde, M. (2013). Factors associated with attrition, mortality, and loss to follow up after antiretroviral therapy initiation: data from an HIV cohort study in India. Global Health Action, 6, 21682. Retrieved from

http://www.pubmedcentral.nih.gov/articlerende r.fcgi?artid=3773168\&tool=pmcentrez\&renderty pe $=$ abstract

ASEAN. (2011). ASEAN Declaration of Commitment: Getting To Zero New HIV Infection, Zero Discrimination, Zero AIDS-Related Deaths., 1-9.

Bekolo, C. E., Webster, J., Batenganya, M., Sume, G. E., \& Kollo, B. (2013). Trends in mortality and loss to follow-up in HIV care at the Nkongsamba Regional hospital, Cameroon. BMC Research Notes, 6(1), 512. https://doi.org/10.1186/1756-0500-6-512

Berheto Tezera Moshago, Demissew Berihun Haile, and S. M. (2014). Predictors of Loss to follow-up in Patients Living with HIV/AIDS after Initiation of Antiretroviral Therapy. North American Journal of Medical Sciences, 6(9), 453-459. Retrieved from http://www.ncbi.nlm.nih.gov/pubmed/2531739 0

Cornell, M., Lessells, R., Fox, M. P., Garone, D. B., Giddy, J., Fenner, L., ... Boulle, A. (2014). Mortality Among Adults Transferred and Lost to Follow-up From Antiretroviral Therapy Programmes in South Africa: A Multicenter Cohort Study. Journal Acquir Immune Defic Syndrom, 67(2), e67-e75.

Dalal, R. P., Macphail, C., Mqhayi, M., Wing, J., Feldman, C., Chersich, M. F., \& Venter, W. D. F. (2008). Characteristics and outcomes of adult patients lost to follow-up at an antiretroviral treatment clinic in johannesburg, South Africa. Journal of Acquired Immune Deficiency Syndromes (1999), 47(1), 1017. https://doi.org/10.1097/QAI.0b013e31815b833 a

Denise, E., Mhairi, M., \& Ian, S. (2013). Increased risk of mortality and loss to follow-up among HIV positive patients with oropharyngeal candidiasis and malnutrition prior to ART initiation - A retrospective analysis from a large urban cohort in Johannesburg, South Africa. National Institutes of Health, 1-18. https://doi.org/10.1016/j.oooo.2011.09.004.Incr eased

Deribe, K., Hailekiros, F., Biadgilign, S., Amberbir, A., \& Beyene, B. K. (2008). Defaulters from antiretroviral treatment in Jimma University Specialized Hospital, Southwest Ethiopia. Tropical Medicine \& International Health : TM \& IH, 13(3), 328-33. $\quad$ https://doi.org/10.1111/j.13653156.2008.02006.x

Edwards, J. K., Cole, S. R., Westreich, D., Moore, R., Mathews, C., Geng, E., ... Mugavero, M. J. (2014). 
Loss to clinic and five-year mortality among HIVinfected antiretroviral therapy initiators. PloS One, 9(7), e102305. https://doi.org/10.1371/journal.pone.0102305

Fox, M. P., Brennan, A., Maskew, M., MacPhail, P., \& Sanne, I. (2010). Using vital registration data to update mortality among patients lost to follow-up from ART programmes: Evidence from the Themba Lethu Clinic, South Africa. Tropical Medicine and International Health. https://doi.org/10.1111/j.13653156.2010.02473.x

Haile, K. T. and F., \& Mekelle. (2014). Predictors of Loss to Follow Up of Patients Enrolled on Antiretroviral Therapy: A Retrospective Cohort Study. Journal of AIDS \& Clinical Research, 5(12). https://doi.org/10.4172/2155-6113.1000393

Hønge, B. L., Jespersen, S., Nordentoft, P. B., Medina, C., da Silva, D., da Silva, Z. J., ... Wejse, C. (2013). Loss to follow-up occurs at all stages in the diagnostic and follow-up period among HIV-infected patients in Guinea-Bissau: a 7-year retrospective cohort study. BMJ Open, 3(10), e003499. https://doi.org/10.1136/bmjopen-2013-003499

Kate Clouse, Audrey Pettifor, Mhairi Maskew, Jean Bassett, Annelies Van Rie, Cyinthia Gay, Frieda Behets, lan Sanne, and M. P. F. (2014). Initiating ART when presenting with higher CD4 counts results in reduced loss to follow-up in a resourcelimited setting, 27(4), 645-650. https://doi.org/10.1097/QAD.0b013e32835c12f 9.Initiating

Kemenkes RI. (2011). Pedoman Nasional Tatalaksana Klinis Infeksi HIV dan Terapi Antiretroviral Pada Orang Dewasa.

Kemenkes RI. (2014). Laporan Situasi Perkembangan HIV\&AIDS di Indonesia Tahun 2014.

Lebouche, B., Yazdanpanah, Y., Gerard, Y., Sissoko, D., Ajana, F., Alcaraz, I., ... Mouton, Y. (2006). Incidence rate and risk factors for loss to followup in a French clinical cohort of HIV-infected patients from January 1985 to January 1998, 140145.

Lwanga, S. K.; Lemeshow, S. (1991). Sample size determination in health studies: a practical manual.

Mocroft, A., Kirk, O., Aldins, P., Chies, A., Blaxhult, A., Chentsova, N., ... Lundgren, J. D. (2008). Loss to follow-up in an international, multicentre observational study. HIV Medicine, 9(5), 261-9. https://doi.org/10.1111/j.14681293.2008.00557.x

Mugisha, V., Teasdale, C. a, Wang, C., Lahuerta, M., Nuwagaba-Biribonwoha, H., Tayebwa, E., ... Abrams, E. J. (2014). Determinants of mortality and loss to follow-up among adults enrolled in HIV care services in Rwanda. PloS One, 9(1), e85774. https://doi.org/10.1371/journal.pone.0085774

Ndiaye, B., Ould, K., Salleron, J., Bataille, P., Bonnevie, F., Cochonat, K., ... Yazdanpanah, Y. (2009). Original article Incidence rate and risk factors for loss to follow-up in HIV-infected patients from five
French clinical centres in Northern France January 1997 to December 2006, (December 2006), 567-575.

Ochieng-Ooko, V., Ochieng, D., Sidle, J. E., Holdsworth, M., Wools-Kaloustian, K., Siika, A. M., ... Braitstein, P. (2010). Influence of gender on loss to follow-up in a large HIV treatment programme in western Kenya. Bulletin of the World Health Organization, 88(9), 681-8. https://doi.org/10.2471/BLT.09.064329

Odafe, S., Idoko, O., Badru, T., Aiyenigba, B., Suzuki, C., Khamofu, H., ... Chabikuli, O. N. (2012a). Patients' demographic and clinical characteristics and level of care associated with lost to follow-up and mortality in adult patients on first-line ART in Nigerian hospitals. Journal of the International AIDS Society. https://doi.org/10.7448/IAS.15.2.17424

Odafe, S., Idoko, O., Badru, T., Aiyenigba, B., Suzuki, C., Khamofu, H., ... Chabikuli, O. N. (2012b). Patients' demographic and clinical characteristics and level of care associated with lost to follow-up and mortality in adult patients on first-line ART in Nigerian hospitals. Journal of the International AIDS Society, 15(2), 17424. Retrieved from http://www.pubmedcentral.nih.gov/articlerende r.fcgi?artid=3494164\&tool=pmcentrez\&renderty pe=abstract

Somi, G., Keogh, S. C., Todd, J., Kilama, B., Wringe, a, van den Hombergh, J., ... Zaba, B. (2012). Low mortality risk but high loss to follow-up among patients in the Tanzanian national HIV care and treatment programme. Tropical Medicine \& International Health: TM \& IH. https://doi.org/10.1111/j.1365-

3156.2011.02952.x

Sugiyono. (2011). Statistika untuk Penelitian. Bandung.

Tran, D. A., Ngo, A. D., Shakeshaft, A., Wilson, D. P., Doran, C., \& Zhang, L. (2013a). Trends in and Determinants of Loss to Follow Up and Early Mortality in a Rapid Expansion of the Antiretroviral Treatment Program in Vietnam: Findings from 13 Outpatient Clinics. PLOS ONE. https://doi.org/10.1371/journal.pone.0073181

Tran, D. A., Ngo, A. D., Shakeshaft, A., Wilson, D. P., Doran, C., \& Zhang, L. (2013b). Trends in and determinants of loss to follow up and early mortality in a rapid expansion of the antiretroviral treatment program in Vietnam: findings from 13 outpatient clinics. PloS One, 8(9), e73181. https://doi.org/10.1371/journal.pone.0073181

UNAIDS. (2012). UNAIDS World AIDS Day Report | 2012.

UNAIDS. (2013a). Global Update On HIV Treatment 2013 :, (June).

UNAIDS. (2013b). HIV in Asia and the Pasific. Retrieved from http://www.unaids.org

WHO. (2013). Consulidated Guidelines on The Use Of Antiretroviral Drugs For Treating And Preventing HIV Infection Recommendations For A Public Health Approach, (June). 
Wubshet, M., Berhane, Y., Worku, A., \& Kebede, Y. (2013). Death and seeking alternative therapy largely accounted for lost to follow-up of patients on ART in northwest Ethiopia: a community tracking survey. PloS One, 8(3), e59197. https://doi.org/10.1371/journal.pone.0059197
Zhou, J., Tanuma, J., Chaiwarith, R., Lee, C. K. C., Law, M. G., Kumarasamy, N., ... Lim, P. L. (2012). Loss to Followup in HIV-Infected Patients from AsiaPacific Region: Results from TAHOD. AIDS Research and Treatment, 2012, 375217. https://doi.org/10.1155/2012/375217 